\title{
Decision-Making of Football Referees in Indonesia
}

\author{
Mochamad Yamin Saputra*, Komarudin Komarudin, Herman Subarjah, Yusuf Hidayat \\ Sports Education \\ Universitas Pendidikan Indonesia \\ Bandung, Indonesia \\ *mochyamins@upi.edu,komarudin_pko@upi.edu,hermansubarjah@upi.edu, yusufhidayat@upi.edu
}

\begin{abstract}
The decision of the soccer referee in a match will affect the outcome of the match, whether it is about an offense or simulation, the player is in an offside or outside position. In Indonesia League 1, there are many factors that influence the referees 'and assistant referees' decisions. One of them is the host factor, distance and point of view, and the mentality of the referees themselves, so that researchers have the desire to know how many referees and assistant soccer referees decides on a decision. Related to matches in League 1 of 2017/2018. In this study the researchers used a descriptive method with a population using FIFA referees totalling 5 people and assistant referees totalling 5 people and the sample using purposive sampling so that only 5 referees and 5 assistants were sampled, with the number of matches up to half the 2017/2018 season. The author's observations obtained that the referee took the decision in the match entirely, the referee 646 decisions consisting of violations $89.47 \%$, and the bias was $10.53 \%$ and the assistant referee took the offside decision. The conclusion of this study is that the decision making by referees and referees' assistants has a very small bias level.
\end{abstract}

\section{Keywords: decision-making, referee, soccer}

\section{INTRODUCTION}

Football is one of the leading sports in the world [1], a world without soccer is unimaginable. A world without football cannot be imagined in what form. The phenomenon of football exceeds the fuck in the world, FIFA has 207 members worldwide while the UN has only 192 countries. In game sports, the existence of a factor of pleasure, excitement, sadness, cheating, injustice and others is a factor that often occurs in sports games, football is no exception. When a team loses the player, official, the audience will vent their sadness, a joy will come when the victory is won by a team and the audience will win the victory, and there is also anger from the audience or player due to an injustice from the referee in leading the match [2].

In the game of football many elements are involved in it, players who play in the field, reserve players, coaches, managers, referees, health workers, the media, and also the audience. All elements involved are one and the others have their respective duties, in their duties one with another must have a feeling of mutual respect for one another so that the match can run according to applicable rules [3]. In this study the researchers only looked at the elements and role of the referee in leading the match in Indonesian League 1.
Competition in Indonesia always presents a competitive competition in it so that a champion can be determined in the last matches, competition between big clubs in Indonesia such as Arema, Persib, Persija, Persipura, and other big clubs is a match that awaited by many parties resulting in competitive competition in a competition. This is a high selling point that will benefit the club and its league organization itself. In a competition there are many supporting factors, one of which is the referee. Indonesia has 5 referees licensed FIFA and 5 assistant referees licensed by FIFA. A referee in leading a match requires excellent physical abilities, they must always move to get the ideal position, so that each event will be clearly seen and can decide the event based on what is seen, not based on responses from other things. Football referees in a match must move about $10-12 \mathrm{~km}$ with $10-15 \%$ of physical activity in high speed, while for assistant referees to move around 6-7 km with $15-20 \%$ high speed [4].

The referee must always move and look for an ideal position so that in making his decision in accordance with applicable regulations and confident of his decision, a football referee when leading a match makes a decision about 140 decisions from an average of 41 incidents [5]. The number of decisions to be taken by a referee in a match requires that a referee has a high level of concentration, and a high concentration can be had if he has good fitness. In a prime condition or fit, a referee will have a distance between events with a relatively close position, and also has a very clear and open perspective, so that the decisions taken will be convincing and not doubt. In the English league the minimum distance between events with a referee covers $20 \mathrm{~m}$ and the average English referee moves and follows the path of the ball is 17.7 $\mathrm{m}$ [6]. Then the Indonesian referee is at a distance, there is no specific research to discuss about it, even though it is very good for the development of Indonesian referees.

A referee when leading a match is assisted by two assistant referees who have the duty of assisting referees in any event that is not visible to the referee, in particular is to see or detect offside positions carried out by attacking players in accordance with the rules of the game article 11 in the rule of the game FIFA (2017/2018). The assistant referee in detecting the offside attacker must move to follow the last two defenders during the match [7]. In addition to following the last two defenders, the assistant referee must also be able to predict who gives the attacking player bait, where the ball is played, in what situations the ball is played and where the attacking player's 
position before the ball is played, from these positions an assistant referee must have an angle ideal view [8].

The decision of the referee and assistant select wrong or biased in making decisions, but the decision will be based on things that are intentional or unintentional mistakes. Actions that are not deliberately decided by the referee and the assistant referee are based on the referee's being a human being who is inseparable from an error, this is the nature of humans [9]. Deliberate decisions are intentionally motivated by an element of pressure or psychological disturbance from the referee before and during the lead of the match so that the decision he made will be biased [10]. Basically a referee will not harm a team, because they have been sworn in as a court judge and they will bear all the consequences of the decisions that have been taken.

The purpose of this study is to provide an overview of how and assistants in making decisions in the field, especially article 12 and article 11, so that in the future it can be discussed in accordance with the problems in decision making and how to improve it.

\section{METHOD}

The method used in this research was descriptive method. The population in this study were all FIFA Indonesia referees, amounting to 5 referees and 5 assistants. The sample in this study was taken using a purposive sampling technique, where researchers took 5 referees and 5 assistants who served in League 1 Indonesia in 2018. In the data collection conducted by researchers is each referee and assistant referee only taken when serving in League 1 in half the competition season. In collecting data the researcher only observes from the video of the match, so it can be seen how many times the referee gives a decision regarding the violation or not, and whether the violation should be given a yellow card or a red card. The instrument used is the referees' decision making in making article 12 or violations and unsportsmanlike conduct (FIFA: 2017/2018), while the referee's assistant only makes decisions on article 11, which is about offside (FIFA: 2017/2018). Analysis of the data used is a percentage, by calculating the percentage of each decision taken by the referee and the assistant referee.

\section{RESULTS AND DISCUSSION}

\section{A. Results}

After the data from the sample is known, the authors then analyse the data obtained. The test results and data analysis are calculated to get the average value and standard deviation. The results of the referee's decision in the League 1 of Indonesia are as follows:

TABLE I. RESUlTS OF CALCULATION OF AVERAGE VALUES AND STANDARD INTERSECTIONS

\begin{tabular}{|l|l|l|l|}
\hline Name & Total & $\begin{array}{c}\text { Average } \\
\text { Value }\end{array}$ & \multicolumn{1}{|c|}{$\begin{array}{c}\text { Standard } \\
\text { Deviation } \\
(\mathbf{S})\end{array}$} \\
\hline Referee & 646 & 129,2 & 10,19 \\
\hline Asistant Referee & 86 & 17,2 & 2,48 \\
\hline
\end{tabular}

From table 1 it can be explained that the results of processing the observation data of referee decisions in Liga 1 Indonesia obtained an average score, and standard deviation, for referees 646 the total number of decisions taken by referees, 129.2 average values, and standard deviations 10.19 , and the assistant referee's total offside decision was 86 decisions, an average value of 17.2 and a standard deviation of 2.486. After knowing the value of the average, and the standard deviation, the authors then proceed with data processing and analysis.

TABLE II. PERCENTAGE Results OF REFEREES' DECISIONS IN LEAGUE 1 INDONESIA

\begin{tabular}{|l|l|l|l|l|}
\hline Name & Fouls & Persen \% & Bias & Persen \% \\
\hline Referee & 578 & 89,47 & 68 & 10,53 \\
\hline Total & 646 & \multicolumn{4}{|l}{} \\
\hline
\end{tabular}

From the results of the calculation of the percentage, that the decision of the referee decides an incident of violation is 578 decisions or $89.47 \%$ while a decision that is considered biased is 68 decisions from the referee with $10.53 \%$. All referees 'decisions are seen and analysed by researchers and referees' assessors and states that out of a total of 646 violations deemed by referees in accordance with article 12 (FIFA 2017/2018) the referee decides only a decision that is considered biased and not in accordance with the law of the games with a percentage of 10.53 percent or present on a very small scale. Refractive decisions made by referees in a match can be determined by various factors, can be from obstructed views or the position of the referee that is less than ideal, pressure from the audience, players, and official teams, and also psychological factors from the referee itself.

TABLE III. Percentage Results of ReFEREE Assistant DeCISIONS IN LIGA 1 INDONESIA

\begin{tabular}{|l|l|c|c|c|}
\hline \multicolumn{1}{|c|}{ Name } & Offside & $\begin{array}{c}\text { Persen } \\
\boldsymbol{\%}\end{array}$ & Bias & $\begin{array}{c}\text { Persen } \\
\boldsymbol{\%}\end{array}$ \\
\hline Asisten Referee & 86 & 89,58 & 10 & 10,42 \\
\hline Total & 96 & \multicolumn{4}{|l}{} \\
\hline
\end{tabular}

From the calculation of this percentage, of the total decisions taken by the assistant referee regarding offside are 96 decisions, of which 86 decisions are said to be offside by the assistant assistant and 10 decisions are said to be biased, or $10.42 \%$. Of course this becomes a problem in a match especially an offside decision taken by the assistant referee will deliver a team to score. The decision taken by the assistant referee, especially in determining offside is a very difficult thing, where the assistant referee must always move in line with the last two defenders and always see the ball to be passed. Of course this requires foresight and a routine training process.

\section{B. Discussion}

From the calculation of these data it can be seen that the referees and referee assistants in providing a decision in the field very much, with a total of 646 decisions or an average of 86 decisions in each match and having to adjust to applicable regulations is not an easy thing, the referee must be able to predict and ascertain the decision he made, whether violation 
or not, whether it should be a yellow card or a red card. From each decision taken it is very possible the existence of an error or bias, because of the function of the human beings themselves [9]. In this research, there is a bias decision which is relatively small. But the small bias is still a problem for a referee and assistant referee because with this bias it is likely to have an influence on the final score of a match [11]. The results of this study the referee took decisions in an average match of 129.2 while the assistant referee in making offside decisions was 17.2 per match. From the decision taken there is a decision that is considered referee biased regarding the decision of the violation is $10.53 \%$ of the referee's error in the decision of the violation and $10.42 \%$ for the assistant regarding the offside decision. This result certainly does not reflect the overall match in Indonesia, because referee sampling and matches tend to be small. In another study stated that there was an error rate of $14.2 \%$ for referees and $12.7 \%$ for assistant referees [12].

The occurrence of bias or error decisions made by the referee occurs because several factors can be intentional or unintentional and decisions that are based on internal influences or outside influences. There are several factors according to the authors who lay the background for referees' decisions, namely physical, psychological, and understanding rules of the game.

Physical condition. This first aspect is an obligation for a referee and assistant referee before they will be on duty. They must pass a physical test before the competition takes place, if they do not pass the physical test then they are not allowed to lead a match. In the Indonesian league, every referee who will be involved in the competition must follow refresher referees conducted by PSSI, each referee is obliged to follow these activities if they wish to serve in League 1 Indonesia. The function of physical ability itself in referee performance is the referee must always move to follow the game and strive to always be close to the incident so that the decision given will be accurate, besides the referee and assistant referee must always move in a match following the match and be asked not far from the incident [7]. The referee must find the right point of view to decide an event, so the referee must try to move if his position is obstructed, so that the physical factors determine the referee and assistant referee in decision making [13].

For the assistant referee in regards to determining offside, the assistant referee must have a good viewpoint between the two last defenders, following where the ball will be played, where the attacker's starting position will touch the ball and where the ball will be played [14]. In the author's observations regarding the position of the referee in every decision, especially when there is a backlash is very far from the event that resulted in the decision became hesitant In addition, the assistant referee is often left behind or is not aligned with the last two defenders, even though his decision is correct, and the assistant referee is too hasty in deciding an event, even though the one who will control the ball is a player who is not in an offside position. This is a problem that must be corrected by the Indonesian football organization.

Psychological. In psychological terms associated with a threat to the referee that occurs before, during and after the match. In this case the threat that is often experienced by football referees in Indonesia is the presence of pressure from the audience, players, and officials. A referee who has experienced a threat will affect psychological, concentration, performance, and motivation so that the decisions taken will not be accurate [2]. A threat or pressure experienced by the referee is divided into two forms namely physical and verbal [15]. Many improvements were made by PSSI and the New Indonesian league operator to anticipate threat factors made by players, coaches, managers, and also spectators to referees and referees assistants, namely by the issuance of strict rules regarding threats to referees, the result is in league 1 Indonesia decreased level of physical threats committed by players, coaches, officials and spectators to referees. But verbal threats are still often experienced by referees, both from players, coaches, and spectators. In addition to an external threat, an internal motivation influences the referee himself, a referee who has his own desire to be a referee will have better selfcontrol, compared to referees who are motivated because of economic factors they will be forced to serve and will even affect the performance [15].

Understanding the rules of the game is a must for a referee, how a referee will decide a problem if he does not master the rules. Football rules every year there are always changes, so the referee and assistant referees must always be updated about the latest regulations. Regarding this understanding, it is not only the referees who must master, but the coaches, players, spectators must master and recognize the rules that apply, so that there will be mutual respect between professions. One study said that understanding the rules of the game players, coaches, spectators, media and components related to football is very low [16].

A referee and assistant referee must have all three factors and it is a must to continue to develop these components, understanding the understanding of rules is a referee thing that must be mastered by the referee and assistant referee, then the physical condition of both the referee and referee assistant are in a position that good for making decisions [13]. After a good position then the next is whether a referee and the assistant referee dare to decide on an incident, and this is related to psychological factors, and this is the focus of the study in subsequent studies.

In this study the understanding of referees and assistant both as well as physical conditions that have passed the physical test, psychological factors are very dominant for referees and assistant referees in decision making.

\section{CONCLUSION}

From the results of research that has been done, it can be concluded that the referee's decision to lead a soccer match in League 1 Indonesia regarding article 12 or violation and unsportsmanlike conduct had a relatively small bias value, while the referee's assistant regarding article 11 or offside obtained a very small bias value. 
[10] F.L. Philippe, R.J. Vallerand, J. Andrianarisoa and P. Brunel, "Passion in referees: Examining their affective and cognitive experiences in sport situations," Journal of Sport \& Exercise Psychology, vol. 31, pp. 77-96, 2009.

[11] P. Dawson and S. Dobson, "The influence of social pressure and nationality on individual decisions: Evidence from the behaviour of referees," Journal of Economic Psychology, vol. 31, pp. 181-191, 2010.

[12] J. Mallo, E. Navarro, J.M. Garcia-Aranda, B. Gilis and W. Helsen, "Activity profile of top-class association football referees in relation to performance in selected physical tests," Journal of Sports Sciences, vol. 25, pp. 805-813, 2007.

[13] Mochamad Y.S, Herman S, Komarudin, Yusuf H, "The physical ability of the assistant referee in decision making in the indonesia. Advances in Health Sciences Research," vol. 11, pp. 164-166, 2018 [The 3rd international conference on sport science, health, and physical education (ICSSHPE 2018)].

[14] P. Catteeuw, B. Gilis, J. Wagemans and W. Helsen, "Perceptualcognitive skills in offside decision making: Expertise and training effects," Journal of Sport \& Exercise Psychology, vol. 32, pp. 828-844, 2010c.

[15] P. Folkesson, C. Nyberg, T. Archer and T. Norlander, "Soccer referees' experience of threat and aggres-sion: Effects of age, experience, and life orientation on out-come of coping strategy," Aggressive Behavior, vol. 28, pp. 317-327, 2002.

[16] B. Gilis, W. Helsen, P. Catteeuw, E.V. Roie and J. Wagemans, "Interpretation and application of the offside law by expert assistant referees: Perception of spatial positions in complex dynamic events on and off the field," Journal of Sports Sciences, vol. 27, pp. 551-563, 2009. 